Gut, 1985, 26, 776-782

\title{
Gastric acid and pancreatic polypeptide responses to modified sham feeding: indication of an increased basal vagal tone in a subgroup of duodenal ulcer patients
}

\author{
ANNA KOHN, B ANNIBALE, G SURIANO, CAROLA SEVERI, \\ SABRINA SPINELLA, AND G DELLE FAVE \\ From the Ospedale Nuovo Regina Margherita, Divisione di Gastroenterologia, Roma, Cattedra di \\ Gastroenterologia I, Clinica Medica II, Università 'La Sapienza', Policlinico Umberto I, Roma, Italy
}

SUMMARY The effect of sham feeding upon gastric acid secretion and pancreatic polypeptide release was investigated in 28 patients with duodenal ulcer in order to evaluate whether high basal vagal activity is the cause of basal acid hypersecretion in patients with duodenal ulcer and basal secretion higher than $30 \%$ of their peak acid output. The patients were divided into two groups based on the ratio of basal/pentagastrin stimulated peak acid output (BAO/PAO) was higher or lower than 0.30: group $\mathrm{A} n=19(\mathrm{BAO} / \mathrm{PAO} \leqslant 0 \cdot 30)$ and group $\mathrm{B} n=9$ (BAO/PAO $>0 \cdot 30)$. Gastric acid response to sham feeding (SAO) was significantly higher than basal level in group A (SAO: $11.4 \mathrm{mEq} / \mathrm{h}(2.5-20.1)$ vs BAO: $5.2 \mathrm{mEq} / \mathrm{h}(0.8-22.9), \mathrm{p}<0.01$, median (range)) while in group B the acid secretion did not increase with sham feeding (SAO: 9.6 $\mathrm{mEq} / \mathrm{h}(4 \cdot 5-13.6)$ vs BAO: $8.8 \mathrm{mEq} / \mathrm{h}(6 \cdot 3-13 \cdot 8) \mathrm{ns}$, median (range)). A negative correlation $(\mathrm{r}=-0.6118226, \mathrm{p}<0.01)$ was found between acid increase expressed as basal subtracted sham feeding response (SAO-BAO) and $\mathrm{BAO} / \mathrm{PAO}$ ratio of the entire group of duodenal ulcer patients $(n=28)$ suggesting that the greater is basal acid secretory capacity the smaller is acid increase in response to residual vagal activation. Pancreatic polypeptide response to sham feeding was higher in group A than in group B but no correlation $(r=0 \cdot 20, n=28)$ nor individual covariation was found between acid and pancreatic polypeptide secretions during vagal stimulation. Sham feeding did not change serum gastrin. It is concluded that an increased vagal stimulation seems to be the cause of basal hypersecretion in a subgroup of patients with duodenal ulcer. The lack of correlation between the pancreatic polypeptide and acid responses to vagal stimulation interferes with the reliability of pancreatic polypeptide as indicator of vagal tone on gastric parietal cells.

An increased vagal tone has been considered one of the possible mechanisms that could explain the increased basal acid secretion in some duodenal ulcer patients. ${ }^{12}$ Cephalic vagal excitation induced by sham feeding results in a potent gastric secretory stimulation. ${ }^{3-5}$ If high vagal activity in the basal state is the cause of increased basal acid secretion in some duodenal ulcer patients, these patients might be expected to secrete little or no additional acid in response to sham feeding. ${ }^{6}$ Feldman et al, ${ }^{6}$ have therefore considered as suggestive of increased

Address for correspondence: Anna Kohn, MD. Ospedale Nuovo Regina Margherita, Divisione di Gastroenterologia, Via Morosini, 30, 00153, Roma. Italy.

Received for publication 30 October 1985 vagal tone the failure to increase acid secretion after sham feeding of four duodenal ulcer patients, with markedly increased basal acid secretion, expressed by a $\mathrm{BAO} / \mathrm{PAO}$ ratio higher than $\mathbf{0 \cdot 3 0}$.

Pancreatic polypeptide is a 36 amino acid polypeptide, localised in a distinct population of pancreatic cells, ${ }^{78}$ released in part under vagal control. ${ }^{9}{ }^{10}$ Sham feeding produces a rapid increase in plasma pancreatic polypeptide concentrations ${ }^{11-13}$ which is abolished by vagotomy ${ }^{12}$ and/or by atropine administration. ${ }^{13}$ Pancreatic polypeptide secretion is regulated by tonic vagal cholinergic activity ${ }^{14}$ and its concentrations fluctuate synchronously with the spontaneous secretions of gastric acid. ${ }^{15}$ Pancreatic polypeptide and acid secretion, 
however, are not mutually dependent, ${ }^{16}{ }^{17}$ but the coordination in their basal secretions has led to the suggestion that pancreatic polypeptide secretion might serve as an independent indicator of vagal activity on gastric parietal cells. ${ }^{18}$

In order to assess the hypothesis that high basal vagal activity causes the basal acid hypersecretion in some duodenal ulcer patients (having basal secretion rates higher than $30 \%$ of their peak acid output $),{ }^{19}$ patients with duodenal ulcer were divided into two groups by means of their $\mathrm{BAO} / \mathrm{PAO}$ ratio (lower or higher than 0.30 ) and the relationship between basal acid secretion and acid response to sham feeding was investigated. In addition the reliability of pancreatic polypeptide secretion as indicator of vagal activity on gastric parietal cells has been investigated studying the relationship between gastric acid and pancreatic polypeptide secretion under basal conditions and during vagal stimulation.

\section{Methods}

PATIENTS

During a clinical trial to investigate the efficacy of $\mathrm{H}_{2}$ antagonists on healing of duodenal ulcer, 28 outpatients with active duodenal ulcer, established by clinical and endoscopic examination, on their given informed consent, entered this clinical experimental study. These patients were divided into two groups according to their basal to pentagastrin stimulated peak acid output (BAO/PAO) ratio: group $\mathrm{A}$ ) 19 patients with $\mathrm{BAO} / \mathrm{PAO} \leqslant 0 \cdot 30$ (five women, 14 men, mean age 41 years, range 29-80; mean weight $73 \mathrm{~kg}$, range 53-93 kg); and group B) nine patients with $\mathrm{BAO} / \mathrm{PAO}>0.30$ (three women, six men; mean age 38 years, range 31-60 years; mean weight $67 \mathrm{~kg}$, range $49-100 \mathrm{~kg}$ ). All patients showed normal basal serum gastrin concentrations (Table 1).

The patients participated in three different studies (pentagastrin stimulation, modified sham feeding, standard meal), on three different days, at intervals of at least two days.

All tests were done after an overnight fast and any anticholinergic or antisecretory medication was withdrawn at least one week before the study.

\section{PENTAGASTRIN STIMULATION}

Firstly the peak acid output (PAO) as index of maximal secretory capacity was stated by injecting $6 \mu \mathrm{g} / \mathrm{kg}$ of pentagastrin (Gastrodiagnost, Merck) subcutaneously, and BAO/PAO ratio was calculated in order to allot patients to the above mentioned two groups.

\section{SHAM FEEDING}

Sham feeding was carried out using a modified sham feeding technique. ${ }^{3-5}$ Patients were served an appetising meal prepared in a separate building and consisting of $200 \mathrm{~g}$ fillet steak, $150 \mathrm{~g}$ French fried

Table 1 Values of $B A O$ and $P A O$ in group $A$ and group $B$ patients with duodenal ulcer

\begin{tabular}{|c|c|c|c|c|c|}
\hline \multirow[b]{2}{*}{ Patients } & \multicolumn{2}{|c|}{ Group $A(B A O / P A O \leqslant 0 \cdot 3)$} & \multirow[b]{2}{*}{ Patients } & \multicolumn{2}{|c|}{ Group $B(B A O / P A O>0 \cdot 3)$} \\
\hline & $B A O$ & $P A O$ & & $B A O$ & $P A O$ \\
\hline 1 & $7 \cdot 5$ & $26 \cdot 8$ & 1 & $8 \cdot 8$ & $26 \cdot 0$ \\
\hline 2 & $15 \cdot 1$ & $71 \cdot 9$ & 2 & $13 \cdot 8$ & $18 \cdot 4$ \\
\hline 3 & $7 \cdot 1$ & $28 \cdot 6$ & 3 & $8 \cdot 7$ & $19 \cdot 3$ \\
\hline 4 & $10 \cdot 0$ & $52 \cdot 6$ & 4 & $8 \cdot 5$ & $22 \cdot 4$ \\
\hline 5 & $5 \cdot 2$ & $35 \cdot 6$ & 5 & $6 \cdot 8$ & $22 \cdot 2$ \\
\hline 6 & $22 \cdot 9$ & $94 \cdot 0$ & 6 & $12 \cdot 6$ & $30 \cdot 0$ \\
\hline 7 & $4 \cdot 4$ & $27 \cdot 0$ & 7 & $8 \cdot 7$ & $25 \cdot 0$ \\
\hline 8 & $5 \cdot 8$ & $101 \cdot 8$ & 8 & $13 \cdot 2$ & $28 \cdot 7$ \\
\hline 9 & $2 \cdot 5$ & $18 \cdot 3$ & 9 & $11 \cdot 4$ & $30 \cdot 2$ \\
\hline 10 & $2 \cdot 0$ & $28 \cdot 8$ & Median & $8 \cdot 8$ & $25 \cdot 0$ \\
\hline 11 & $7 \cdot 0$ & $25 \cdot 9$ & (range) & $(6 \cdot 8-13 \cdot 8)$ & $(18 \cdot 4-30 \cdot 2)$ \\
\hline 12 & $4 \cdot 8$ & $25 \cdot 6$ & & & \\
\hline 13 & $0 \cdot 8$ & $41 \cdot 8$ & & & \\
\hline 14 & 0.9 & $20 \cdot 0$ & & & \\
\hline 15 & $5 \cdot 3$ & $18 \cdot 9$ & & & \\
\hline 16 & $6 \cdot 5$ & $40 \cdot 7$ & & ${ }^{\prime}$ & \\
\hline 17 & $2 \cdot 2$ & $31 \cdot 1$ & & & \\
\hline 18 & $1 \cdot 8$ & $15 \cdot 7$ & & & \\
\hline 19 & $2 \cdot 1$ & $32 \cdot 8$ & & & \\
\hline Median & $5 \cdot 2$ & $28 \cdot 8$ & & & \\
\hline (range) & $(0 \cdot 8-22 \cdot 9)$ & $(15 \cdot 7-101 \cdot 8)$ & & & \\
\hline
\end{tabular}

BAO group A vs BAO group B: ns. PAO group A vs PAO group B: ns. 
potatoes and $250 \mathrm{ml}$ water. The food was tested, chewed, and spat out. The modified sham feeding procedure lasted 30 minutes. This length of time was chosen as it was shown that a modified sham feeding of 30 minutes is a powerful stimulus for vagal activation. ${ }^{20}$ Gastric secretion was collected during 60 minutes basal period and for two hours during and after sham feeding. Gastric aspirates were carefully checked for swallowed food particles and few or none were found.

TEST MEAL

A meal identical to that served during sham feeding was offered and completed within 30 minutes.

\section{DETERMINATION OF ACID SECRETION}

A nasogastric tube (modified Levine no 14) was positioned under fluoroscopic control with the radio-opaque tip in the gastric antrum 90 minutes before pentagastrin and sham feeding stimulations.

The gastric residue was completely aspirated and discarded. Collections were made at 15 minute intervals and acid content was titrated to $\mathrm{pH}=7 \cdot 0$ (PHM62 Radiometer, Copenhagen) with $0 \cdot 1 \mathrm{M}$ $\mathrm{NaOH}$.

Basal acid output (BAO) and sham feeding stimulated acid output (SAO) expressed as milliequivalent $\mathrm{H}^{+}$/hour were calculated as the sum of the four consecutive 15 minute outputs during the basal and sham feeding hours respectively. The sum of the two highest consecutive 15 minute outputs after pentagastrin multiplied by two represents the peak acid output by pentagastrin (PAO). Gastric acid secretion was also evaluated as ratio: basal/ pentagastrin stimulated peak acid output (BAO/ PAO) and basal/sham feeding stimulated acid output (BAO/SAO). In order to determine the residual vagal activation $B A O$ value was subtracted from the acid increase in response to sham feeding (SAOBAO $\mathrm{mEq} / \mathrm{h}$ ).

PANCREATIC POLYPEPTIDE AND GASTRIN

Venous blood samples were obtained from a peripheral vein every 15 minutes, three times before sham feeding and test meal and at 5, 10, 15, 30 minutes during and 45, 60, 75, 90, 120 minutes after. Blood samples were collected in EDTA plus aprotinin and plasma, separated by centrifugation, was stored at $-20^{\circ} \mathrm{C}$ until assayed.

Pancreatic polypeptide radioimmunoassay ${ }^{21}$ was carried out by means of anti BPP serum 146-10 (kindly supplied by Dr R A Chance, Lilly Research Laboratories, Indianapolis) at a final dilution of $1: 6,000,000$. Highly purified bovine pancreatic polypeptide was iodinated using a modification of the chloramine-T method. Highly purified human pancreatic polypeptide was used as standard. Free antigen was separated from bound fraction by adding plasma-coated charcoal. The experimental detection limit was $3.75 \mathrm{pg} /$ tube. The within assay coefficient of variation was less than $5 \%$ whereas the between assay coefficient of variation was $14 \%$.

Plasma gastrin concentrations were determined by radioimmunoassay as previously described ${ }^{22}$ using antiserum 2604 (kindly supplied by Professor J F Rehfeld).

Serum pancreatic polypeptide and gastrin measured in each sample are expressed as $\mathrm{pg} / \mathrm{ml}$.

\section{STATISTICS}

All results are expressed as median with total range in brackets, because pancreatic polypeptide concentrations are not normally distributed.

Differences within a group were determined by Wilcoxon's matched pair signed rank test. Differences between groups were determined by Wilcoxon's sum rank test. Correlation was determined by Spearman rank correlation coefficient.

A $p$ value of less than 0.05 was regarded as significant.

Pancreatic polypeptide response was expressed as integrated pancreatic polypeptide response (IPPR) and calculated according to the following formula:

$$
\begin{aligned}
\frac{\Delta P_{0}+\Delta P P_{1}}{2} & \cdot\left(t_{1}-t_{0}\right) \\
& +\frac{\Delta P P_{1}+\Delta P P_{2}}{2} \cdot\left(t_{2}-t_{1}\right) \\
& +\frac{\Delta P P_{n-1}+\Delta P P_{n}}{2} \cdot\left(t_{n}-t_{n-1}\right)
\end{aligned}
$$

$\triangle \mathrm{PP}$ is plasma pancreatic polypeptide concentrations minus basal pancreatic polypeptide concentrations; $t$ is time in minutes, subscripts $0,1,2 \ldots \mathrm{n}$ refer to successive sampling periods $(0=$ basal sample, therefore $\mathrm{PP}_{0}$ is always equal to zero).

The integrated gastrin response (IGR) was calculated according to the previous formula.

\section{Results}

The range of distribution of basal acid output evaluated as a fraction of pentagastrin peak acid output (BAO/PAO) is shown in Figure 1. In the group of patients with $\mathrm{BAO} / \mathrm{PAO} \leqslant 0.30$ (group A) the ratio ranged from 0.02 to 0.28 (median: 0.16 ) and in the group with BAO/PAO $>0.30$ (group B) the ratio ranged from 0.31 to 0.75 (median: 0.38 ). Individual variation of basal acid output evaluated in different days during pentagastrin stimulation and modified sham feeding test did not affect significantly BAO/PAO ratio, except for one case that was 


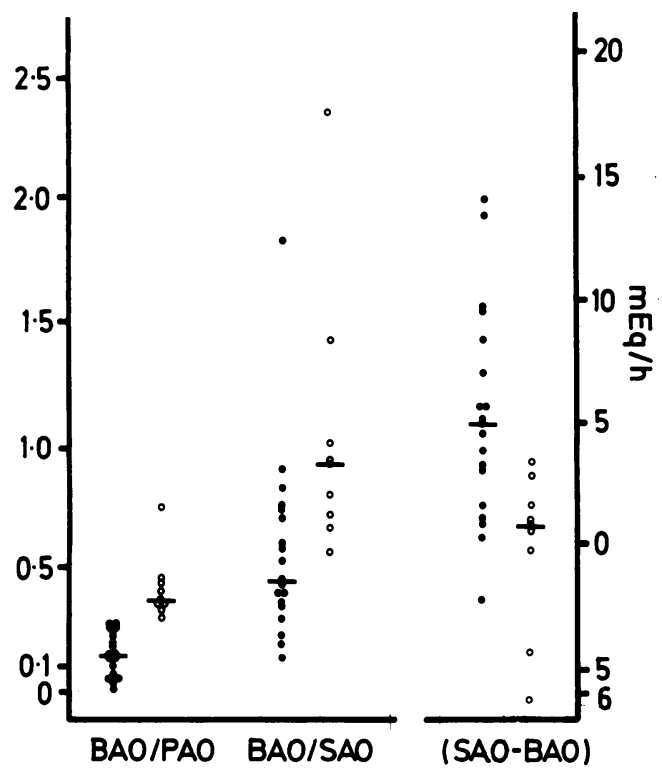

Fig. 1 Ratio of basal acid output to peak acid output (BAO/PAO) and of basal to sham feeding acid output (BAO/SAO) and SAO-BAO in 19 patients with duodenal ulcer and $B A O / P A O \leqslant 0 \cdot 30$ (group $A$ ) (close circles) and in 9 patients with $B A O / P A O>0.30$ (group B) (open circles). Median values are shown as horizontal lines. $p$-values for differences between group $A$ and group $B$ are: $<0.05$ (BAO/PAO); <0.01 (BAO/SAO); <0.01 (SAO-BAO).

discarded.

Figure 1 also shows that gastric acid response to sham feeding, when basal acid output (BAO) is expressed as fraction of sham feeding acid output (SAO) is statistically lower in group $A$ than in group B (BAO/SAO: group A: $0.46(0.15-1.84) v s$ group B: $0.94(0.67-2.35) ; \mathrm{p}<0.01$; median (range)). When the sham feeding stimulated acid secretion is expressed as basal subtracted sham feeding response (SAO-BAO $\mathrm{mmol} / \mathrm{h}$ ) group A showed a statistically higher value than group B (group A: $5(-2 \cdot 1-14 \cdot 2$ ) $\mathrm{mEq} / \mathrm{h}$ vs group $\mathrm{B}: 1(-6 \cdot 1-3.4) \mathrm{mEq} / \mathrm{h} ; \mathrm{p}<0.01$; median (range)). (Fig. 1).

Figure 2 shows the time course of gastric acid secretion in response to sham feeding in both groups of patients. Gastric acid output in response to sham feeding (SAO) was significantly increased in group A (SAO: $11.4 \quad(2.5-20 \cdot 1) \mathrm{mEq} / \mathrm{h}$ vs BAO: $5 \cdot 2$ $(0.8-22.9) \mathrm{mEq} / \mathrm{h} ; \mathrm{p}<0.01$; median (range)) reaching the peak in the second 15 minute period of sham feeding stimulation, while group B did not show increased acid secretion during and after vagal stimulation (SAO: 9.6 (4.5-13.6) $\mathrm{mEq} / \mathrm{h}$ vs BAO: $8 \cdot 8(6 \cdot 8-13 \cdot 8) \mathrm{mEq} / \mathrm{h} ; \mathrm{ns} ;$ median (range)).

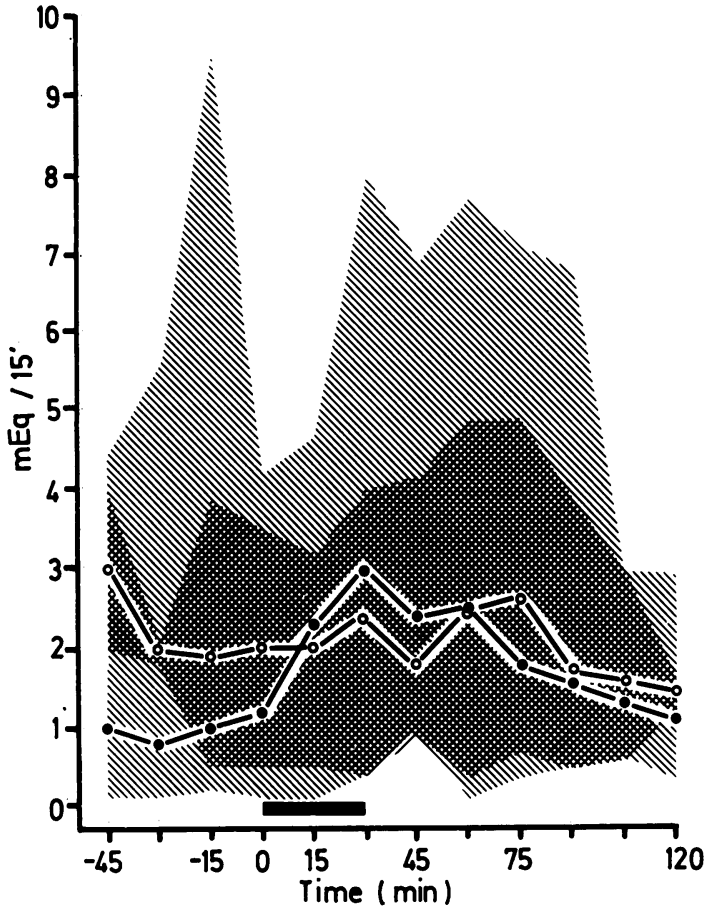

Fig. 2 Time course of the median (range) gastric acid secretion in response to modified sham feeding in twenty eight patients with duodenal ulcer: 19 with $B A O / P A O$ $\leqslant 0.30$ (group $A)(-1)$ range and 9 with $B A O / P A O$ $>0.30$ (group $B)\left(O \_-O\right)$ range. The dark dash ( indicates the length of sham feeding. The acid output in the group A patients ( - is significantly increased $(p<0.01)$ at 15 and 30 min during sham feeding.

Figure 3 shows that in the group of 28 duodenal ulcer patients (group A + group B) there is a negative correlation $(r=-0.6118226, p<0.01)$ between BAO/PAO ratios plotted with SAO-BAO that is, the greater the basal secretion expressed as percentage of peak pentagastrin-stimulated acid output (BAO/PAO), the smaller the acid increase (SAO-BAO) in response to residual vagal activation.

Modified sham feeding led to a significant and rapid increase in serum pancreatic polypeptide concentrations over the basal values in both groups of duodenal ulcer patients (data not shown).

No significant difference was found in the basal values of pancreatic polypeptide between the two groups of patients (group A: $70(26-240) \mathrm{pg} / \mathrm{ml} v s$ group B: 75 (28-268) pg/ml; median (range)).

Table 2 shows the pancreatic polypeptide response to sham feeding evaluated as integrated response (IPPR) during the 30 minutes stimulation; 


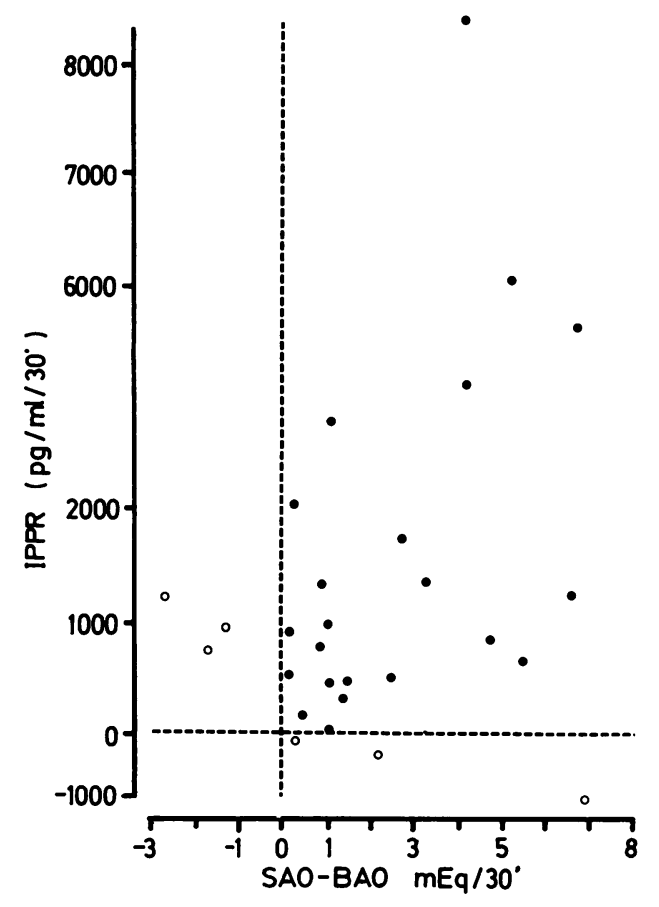

Fig. 3 Correlation $(r=0 \cdot 20)$ between integrated pancreatic polypeptide response $\left(I P P R_{s f}\right)$ and gastric acid increase (SAO-BAO) during the 30 min sham feeding in 28 patients with duodenal ulcer. The open circles beneath basal values, shown by broken lines, indicate three patients who have a gastric acid increase without any pancreatic polypeptide response to sham feeding and three other patients with good pancreatic polypeptide response and no acid increase.

it was two times higher in group A than in group B (973 vs $445 \mathrm{pg} / \mathrm{ml} / 30 \mathrm{~min}$ ), but p value barely missed statistical difference $(p=0.05)$. The pancreatic polypeptide response to standard meal was similar in the two groups of patients (Table 1).

Comparing gastric acid secretion and pancreatic polypeptide serum concentration measured at the

Table 2 Pancreatic polypeptide response to sham feeding $\left(I P P R_{s f}\right)$ and to meal $\left(I P P R_{m}\right)$ expressed as $30 \mathrm{~min}$ integrated response $(\mathrm{pg} / \mathrm{ml} / 30 \mathrm{~min})$ in the group $A$ and in the group $B$ patients with duodenal ulcer

\begin{tabular}{lll}
\hline & $I P P R_{s f}$ & $I P P R_{m}$ \\
\hline $\begin{array}{lll}\text { Group A }(\mathrm{n}=19) \\
\text { BAO/PAO } \leqslant 0 \cdot 30\end{array}$ & $973(-199-6075)$ & $8887 \cdot 5(3245-26500)$ \\
$\begin{array}{cl}\text { Group B }(\mathrm{n}=9) \\
\text { BAO/PAO }>0.30\end{array}$ & $445(-75-1212)$ & $9431 \cdot 3(3362 \cdot 5-20250)$ \\
\cline { 2 - 3 } & $\mathrm{p}=0.05$ & $\mathrm{~ns}$ \\
\hline
\end{tabular}

start of each 15 minute collecting period in the individual patient (seven determinations), no positive covariation was found with a median correlation coefficient of 0.287 , range $(-0.006-0 \cdot 942) \quad(n=28)$. During the 30 minutes of sham feeding test no significant correlation was found between integrated pancreatic polypeptide response (IPPR $R_{\text {ff }}$ ) and the increase in gastric acid secretion (SAO-BAO, $\mathrm{mEq} / 30 \mathrm{~min}$ ) (Fig. 3).

Basal serum gastrin concentrations were similar in both groups of patients (group A: 53 (28-95) pg/ml vs group B: 48 (30-100) pg/ml; ns; median (range)).

Sham feeding did not significantly affect serum gastrin concentrations in both groups of duodenal ulcer patients (Integrated gastrin response (IGR): group A: $37 \cdot 5,(-227-610) \mathrm{pg} / \mathrm{ml} / 30 \mathrm{~min} v s$ group B: $24 \cdot 5(-290-530) \mathrm{pg} / \mathrm{ml} / 30 \mathrm{~min}$; ns; median (range)).

\section{Discussion}

This study provides evidence that duodenal ulcer patients with high basal acid secretion, expressed by a BAO/PAO ratio higher than $0 \cdot 30$, and normal serum gastrin levels, do not show increased acid secretion in response to cephalic vagal activation that is, modified sham feeding procedure.

This study based on a larger series of duodenal ulcer patients, confirms the previous observation reported by Feldman et al. ${ }^{6}$ Both our results and those of Feldman could be explained by the following hypothesis: if high vagal activity under basal conditions is present, little or no additional acid will be secreted in response to vagal stimulation by sham feeding. This hypothesis is further supported by our finding of a negative correlation between basal secretion, expressed as percentage of peak stimulated-acid output (BAO/PAO), and basal subtracted sham feeding response (SAO-BAO) in all 28 patients with duodenal ulcer (Fig. 4). Thus, in duodenal ulcer patients, either with or without basal hypersecretion, the higher their $\mathrm{BAO} / \mathrm{PAO}$ ratio, the lower the acid response to vagal stimulation. The amount of 'vagal tone' could hence be expressed by the degree of $\mathrm{BAO} / \mathrm{PAO}$ ratio.

The BAO/PAO ratio, however, could vary in the same subject, owing to wide variation in basal acid secretion which is affected by such factors as environmental conditions, and emotional state of the individual, with cyclic variation during the day and great differences from day to day. ${ }^{19}$

In our population of patients with active duodenal ulcer only in one case did variation of basal secretion affect $\mathrm{BAO} / \mathrm{PAO}$ ratio. This subject, who was discarded, had been examined on two different occasions: pentagastrin stimulation during clinic and endoscopic ulcer recurrence $(\mathrm{BAO} / \mathrm{PAO}=0 \cdot 32)$ and 


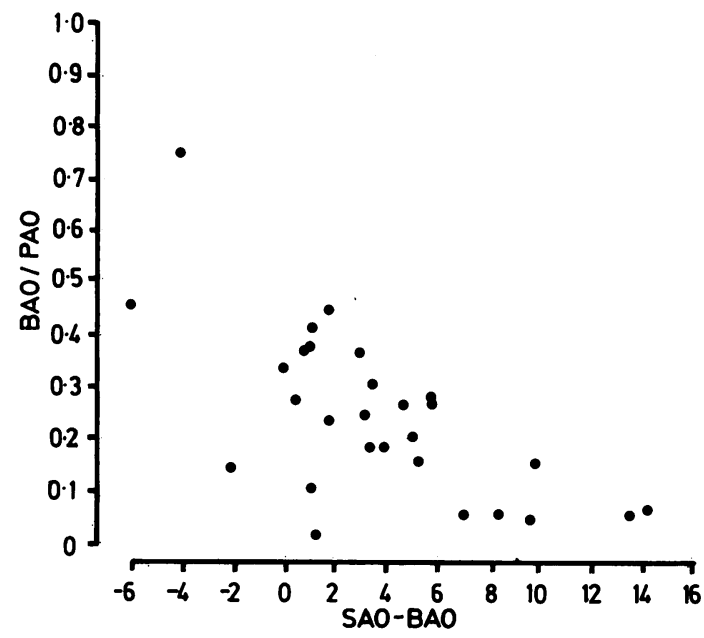

Fig. 4 Correlation ( $r=-0 \cdot 6118226)$ between acid increase in response to modified sham feeding $(S A O-B A O)$ and basal secretion expressed as a percentage of peak pentagastrin-stimulated acid output (BAO/PAO) in 28 patients with duodenal ulcer.

sham feeding test while asymptomatic (BAO/ $\mathrm{PAO}=0 \cdot 19)$.

The lack of stimulation of gastrin release by modified sham feeding, in both groups of patients with duodenal ulcer, is in agreement with other reports, where cephalic stimulation failed to reveal any significant alteration in serum gastrin levels during and after the modified sham feeding. ${ }^{20} 23$ These results and the findings reported by Feldman ${ }^{6}$ that patients with basal hypersecretion caused by hypergastrinaemia, as in gastroinoma or during exogenous gastrin infusion, consistently responded to sham feeding with an increase in acid secretion, rule out a role of gastrin in the lack of gastric acid response in the group of patients with $\mathrm{BAO} / \mathrm{PAO}$ $>0.30$.

Pancreatic polypeptide release during the 30 minute vagal test was twice as high in group $A$ than in group B even if statistical significance was just barely missed $(p=0.05)$. Thus, the pattern of pancreatic polypeptide response in the two groups of patients resembles the acid response obtained by sham feeding.

We are not able to explain this result but some contradictory data should be kept in mind: (1) pancreatic polypeptide response to modified sham feeding varies largely from patient to patient, as found by Schwartz ${ }^{11}$ and as observed in the present study; (2) it is possible to stimulate acid secretion, by sham feeding, without stimulating pancreatic polypeptide secretion and vice versa (Fig. 3: white dots); (3) no correlation or individual covariation were found between pancreatic polypeptide concentrations and acid secretion, during the vagal test, in 28 duodenal ulcer patients (Fig. 3), data in agreement with previous reports. ${ }^{11}$ For these reasons it is difficult to explain the two-fold increase in pancreatic polypeptide concentrations in group A patients; we can only speculate that it was occasional, more than a real event present in each single subject.

Moreover the absence of correlation and individual covariation, seen in our duodenal ulcer patients, between acid and pancreatic polypeptide secretions, questions the reliability of pancreatic polypeptide secretion as independent indicator of 'vagal tone' on gastric parietal cells as already recently discussed. ${ }^{11}{ }^{24}$ Acid secretion, in fact is the results of at least three synergistic mechanisms: gastrin, histamine, and vagal activation, two of which do not seem to affect pancreatic polypeptide secretion and, in turn, vagal neuro-transmission to the acid secretory glands is only partially cholinergic. ${ }^{24} 25$

In conclusion it seems likely that an increased basal vagal tone with basal hypersecretion $(\mathrm{BAO} /$ PAO $>0 \cdot 30$ ) is a recurring condition occurring in a low percentage of patients with duodenal ulcer. It would be interesting to investigate the possible relationship between variations in $\mathrm{BAO} / \mathrm{PAO}$ ratio and some clinical conditions, as ulcer recurrence, in this subgroup of patients.

The study was supported in part by grant no 81.00084 from the National Research Council of Italy (CNR), and by a grant from the State University of Rome, Research Found no 280/ 8.01.10.

A preliminary report of this work has been published in abstract form (Gastroenterology 1983; 84: 1211).

\section{References}

1 Isenberg J, Richardson CT, Fordtran JS. Pathogenesis of peptic ulcer. In: Sleisinger MH, Fordtran JS, eds. Gastrointestinal disease. Philadelphia: W B Saunders, 1978: 792-806.

2 Dragsted LR. A concept of the etiology of gastric and duodenal ulcers. Gastroenterology 1956; 45: 14-26.

3 Richardson CT, Walsh JH, Cooper KA, Feldman M, Fordtran JS. Studies on the role of cephalic-vagal stimulation in the acid secretory response to eating in normal human subjects. J Clin Invest 1977; 60: 435-41.

4 Knutson U, Olbe L. Gastric acid response to sham feeding before and after resection of antrum and duodenal bulb in duodenal ulcer patients. Scand $J$ 
Gastroenterol 1974; 9: 191-201.

5 Feldman M, Walsh JH. Acid inhibition of sham feeding-stimulated gastrin release and gastric acid secretion: effect of atropine. Gastroenterology 1980; 78: 772-6.

6 Feldman M, Richardson CT, Fordtran JS. Effect of sham-feeding on gastric acid secretion in healthy subjects and duodenal ulcer patients: evidence for increased basal vagal tone in some ulcer patients. Gastroenterology 1980; 79: 796-800.

7 Larsson L-I, Sundler F, Håkanson R. Immunohistochemical localisation of human pancreatic polypeptide (HPP) to a population of islet cells. Cell Tissue Res 1975; 156: 167-71.

8 Larsson L-I, Sundler F, Håkanson R. Pancreactic polypeptide postulated hormone: Identification of its cellular storage site by light and electron microscopic immunocytochemistry. Diabetologia 1976; 12: 211-6.

9 Schwartz TW, Stenquist B, Olbe L. Physiology of mammalian PP and the importance of vagal regulation. In: Bloom SR, ed. Gut hormones. Edinburgh: Churchill Livingstone, 1978: 261-4.

10 Adrian TE, Bloom SR, Bryant MG, Polak JM, Heitz PH, Barnes AJ. Distribution and release of human pancreatic polypeptide. Gut 1976; 17: 940-4.

11 Schwartz TW, Stenquist B, Olbe L. Cephalic phase of pancreatic polypeptide secretion studied by sham feeding in man. Scand J Gastroenterol 1979; 14: 313-20.

12 Taylor IL, Feldman M, Richardson CT, Walsh JH. Gastric and cephalic stimulation of human pancreatic polypeptide release. Gastroenterology 1978; 75: 432-37.

13 Feldman M, Richardson CT, Taylor IL, Walsh JH. Effect of atropine on vagal release of gastrin and pancreatic polypeptide. J Clin Invest 1979; 63: 294-8.

14 Schwartz TW, Holst JJ, Fahrenkrug J, Lindkaer, Jensen S, Nielsen OV, Rehfeld JF. Schaffalitzky de Muckadell OB and Stadil F. Vagal, cholinergic regulation of pancreatic polypeptide secretion. J Clin Invest 1978; 61: 781-9.
15 Schwartz TW, Stenquist BO, Olbe L, Stadil F. Synchronous oscillations in the basal secretion of pancreatic polypeptide and gastric acid. Depression by cholinergic blockade of pancreatic polypeptide concentrations in plasma. Gastroenterology 1979; 76: 14-6.

16 Lin T-M, Evans DC, Chance RE, Spray GF. Bovine pancreatic peptide: action on gastric and pancreatic secretion in dogs. Am J Physiol 1977; 232: E311-S.

17 Floyd JC, Fajans SS, Pek S, Chance RE. A newly recognized pancreatic polypeptide: plasma levels in health and disease. Recent Prog Horm Res 1977; 33: 519-70.

18 Schwartz TW. Pancreatic polypeptide as indicator of vagal activity. In: Rehfeld JF, Amdrup E, eds. Gastrins and the vagus. London: Academic Press, 1979: 175-9.

19 Feldman M, Richardson CT. Gastric acid secretion in humans. In: Johnson LR, ed. Physiology of the gastrointestinal tract. Vol. 1. New York: Raven Press, 1981: 693-707.

20 Konturek SJ, Swierczek J, Kwieciep N et al. Gastric secretory and plasma hormonal responses to shamfeeding of varying duration in patients with duodenal ulcer. Gut 1981; 22: 1003-10.

21 Annibale B, Bruzzone R, Severi C et al. Evidence of a non-vagal mechanism of pancreatic polypeptide release in man. Ital J Gastroenterol 1981; 13: 244-7.

22 Delle Fave G, Kohn A, De Magistris L, Mancuso M, Sparvoli C. Effect of bombesin-stimulated gastrin on gastric acid secretion in man. Life Sci 1980; 27: 993-9.

23 Stenquist B, Nilsson G, Rehfeld JF, Olbe L. Plasma gastrin concentrations following sham feeding in duodenal ulcer patients. Scand J Gastroenterol 1979; 14: 305-11.

24 Taylor IL, Feldman M. Pancreatic-polypeptide and the vagus. In: Rehfeld JF, Amdrup E, eds. Gastrins and the vagus. London: Academic Press, 1979: 267-71.

25 Stenquist B, Rehfeld JF, Olbe L. Effect of proximal gastric vagotomy and anticholinergics on the acid and gastrin responses to sham feeding in duodenal ulcer patients. Gut 1979; 20: 1020-7. 